\title{
Density of Kerosene Aluminium Nanofluid used for Regenerative Cooling Applications of Thrust Chambers
}

\author{
Abhinav Kumar, Anil Chamoli, Shahid Khan, Arfaj Ahamed Anwar, J. V. Muruga Lal Jeyan
}

\begin{abstract}
Efficient cooling of thrust chamber is always remaining the key area of research due to the increase in the interest of space exploration programmes. Agencies like NASA, ISRO, SpeceX, BlueOrigin are planning to start commercial flights into the space for common people. To achieve this accuracy and safety both are required and efficient cooling of the thrust chambers is one of them as it has to handle large heat loads twice, first at the time of take-off and secondly, when the vehicle has to land on the ground. ISRO has planned to use kerosene with aluminium nanoparticles for the cooling purposes of the thrust chambers. To achieve higher accuracies, the property variations as a function of temperature and pressure are required so that point to point variation can be visualized comparatively easily. In the present work, density of kerosene and its nanofluid has been studied and in order to use this property variation directly into the simulation software, curve fitting has been done for density of the nanofluid as a function of temperature.
\end{abstract}

Keywords: Thrust chambers, kerosene, nanofluid, heat transfer, pressure drop, regenerative cooling.

\section{INTRODUCTION}

Indian Space Organisation (ISRO) is one of the emerging space agencies who is known for their cheaper and efficient flights, starting from Chandrayan-I to Mars Orbiter Mission (MoM) followed by setting a new world record by successfully putting 104 nano-satellites into their orbit. Now, next plan is to set a new International Space Station of India into the orbit which will increase the research capabilities of Indian scientists in exploring the deep space unknowing facts. Also, the space agency has planned its first man mission to moon which needs more safeguards before launching. In near future, ISRO is also planning to open the gallery for commercial flights for common people like NASA, SpeceX, BlueOrigin. The overall mission of any space programme is to

Revised Manuscript Received on December 02, 2019

* Correspondence Author

Abhinav Kumar*, School of Mechanical Engineering, Lovely Professional University, Phagwara, India. Email: drabhinav@ieee.org

Anil Chamoli, Department of Aerospace Engineering, Lovely Professional University, Phagwara, India. Email: anilchamoli777@gmail.com

Shahid Khan, Department of Aerospace Engineering, Lovely Professional University, Phagwara, India. Email: khan.shahid1171@gmail.com

Arfaj Ahamed Anwar, MRB Engineer, Department of Aerospace Systems, United Technologies Corporation, Ontario, Canada. Email: arfaj2000@hotmail.com

J. V. Muruga Lal Jeyan, Department of Aerospace Engineering, Lovely Professional University, Phagwara, India. Email: jvmlal@ymail.com

have heavy payload with lower weight to power ratio. Thus, in order to lower the overall rocket weight by using the light metals or by reducing the section thicknesses and by improving the overall rates of heat transfers. Many people have used many combinations for the thrust chamber cooling [1]-[8]. Researchers from Liquid Propulsion Systems Centre (LPSC) have suggested using kerosene-alumina based nanofluid for the cooling of thrust chambers [9]. They have identified that kerosene-alumina nanofluid is having potential for the efficient cooling of the thrusters and it can handle large heat loads. However, they have concluded that there is possibility of increasing pressure drop also with the increase in the overall heat transfer rates. LPSC scientists studied the convective heat transfer problem of the Kerosene-alumina nanofluid where they have calculated Merit number to conclude the overall convective heat transfer performance [9]. Merit number is a ratio between rates of heat transfer enhancement to the increase in pressure drop. Pressure drop is significantly affected by the density variations thus in the present study density variations as a function of temperature (275-475 K), pressure (1-10 bar) and nanoparticles volume fraction (phi $=1 \%$ to $5 \%$ ) has been studied.

\section{DENSITY OF BASE-FLUID AND NANO-FLUID}

Density of dodecane which is a surrogate fuel of kerosene has been extracted from NIST database for a temperature and pressure ranges from $275 \mathrm{~K}$ to $475 \mathrm{~K}$ and $1 \mathrm{bar}$ to $10 \mathrm{bar}$ respectively. The density of aluminium nanoparticles $\left(\mathrm{Al}_{2} \mathrm{O}_{3}\right)$ has been taken from commercial a supplier $(99 \%$ Aluminium nanoparticles grade) which is $3880 \mathrm{~kg} / \mathrm{m}^{3}$. To calculate the effective density of the dodecane-aluminium nanofluid following relation has been used [10]:

$\rho_{n f}=\phi \rho_{n p}+(1-\phi) \rho_{b f}$

$\phi$ (phi) is a volume fraction, $\rho_{b f}$ is density of base fluid i.e. dodecane and $\rho_{n p}$ is the density of nanoparticles.

Fig. 1 shows the density $\left(\mathrm{kg} / \mathrm{m}^{3}\right)$ and viscosity $(\mu \mathrm{Pa} . \mathrm{s})$ variation for base fluid (dodecane) with temperature and Fig.2 shows the variation in thermal conductivity $(\mathrm{W} / \mathrm{mK})$ and specific heat $(\mathrm{kJ} / \mathrm{kgK})$ of base fluid. In this work, the study is focussed on density of nanofluid which can be calculated from (1). 


\section{Density of Kerosene Aluminium Nanofluid used for Regenerative Cooling Applications of Thrust Chambers}

It can be noticed from Fig. 3 that the density of the nanofluid is found to increase with the concentration of nanoparticles and found to decrease with temperature which $\left(\rho, \mu, c_{p}, k\right)=\frac{p_{0}+a_{1} T+b_{1} P+b_{2} P^{2}+b_{3} P^{3}}{1+a_{2} T+a_{3} T^{2}+a_{4} T^{3}+b_{4} P+b_{5} P^{2}}$ is obvious fact. Thus, with the addition of nanoparticles there is a chance of more pressure drop which will affect the Merit number. Therefore, cautious investigation is required while choosing the optimum concentration of the alumina nanoparticles.

In order to quantify these variations in effective density of nanofluid, an attempt has been made to fit the property with pressure and temperature dependent correlation (2). Table I and Table II shows the correlation coefficients and standard $R^{2}=1-\frac{\sum_{i=1}^{N}\left(f_{i}^{c a l}-f_{i}^{n i s t}\right)^{2}}{\left(f_{i}^{c a l}-f_{i}^{\text {mean }}\right)^{2}}$

where $f_{i}^{\text {mean }}=\frac{1}{N} \sum_{i=1}^{n} f_{i}^{c a l}$ calculated using (3) which is found near to 1 .

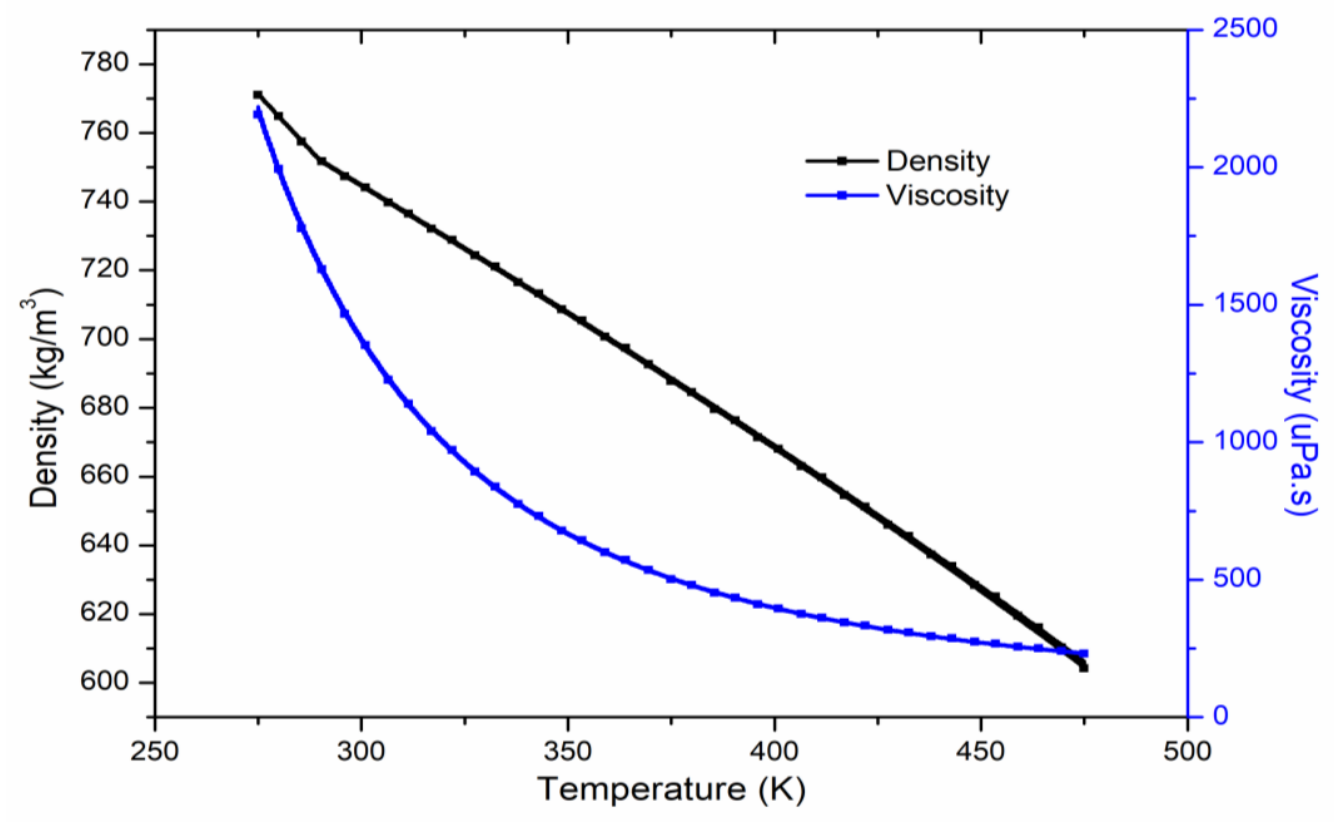

Fig. 1 Density and Viscosity of basefluid

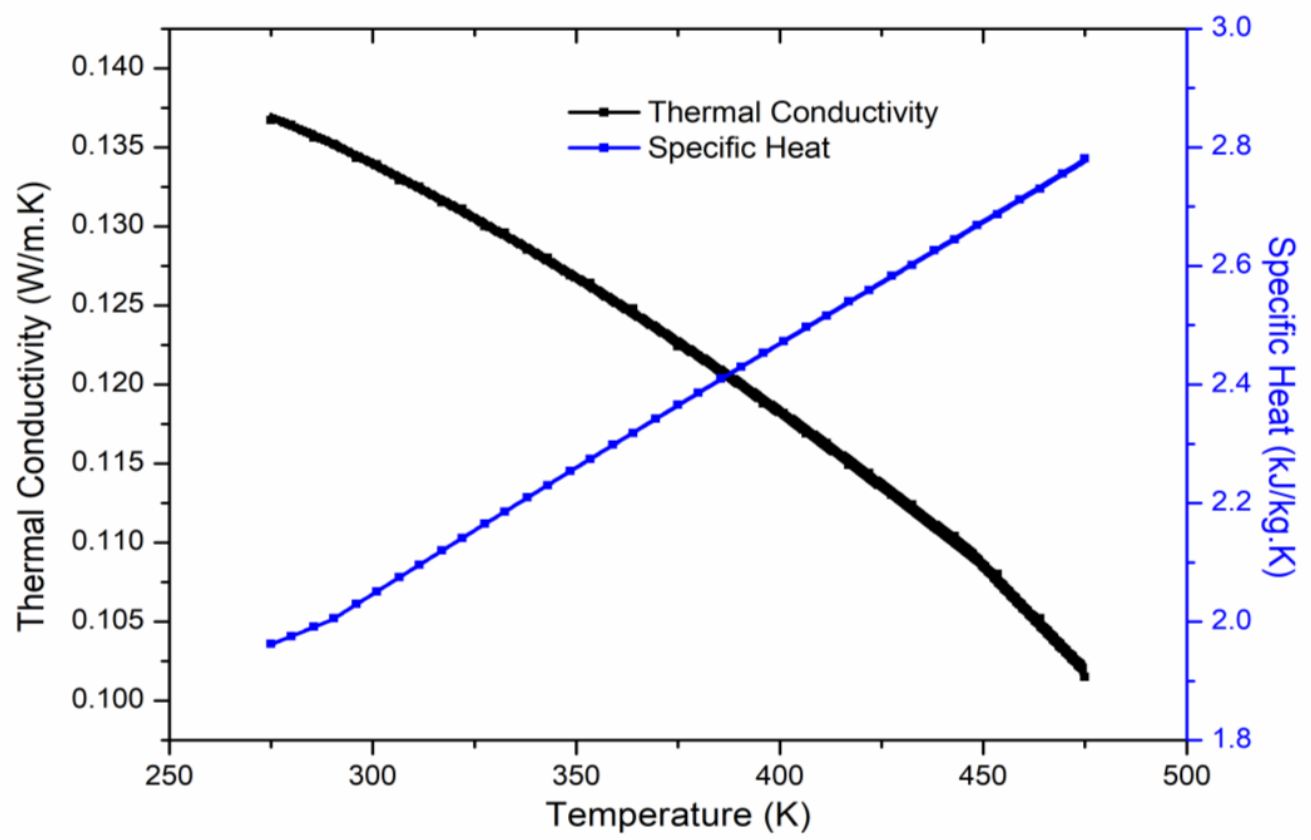

Fig. 2 Thermal Conductivity and Specific Heat of basefluid 


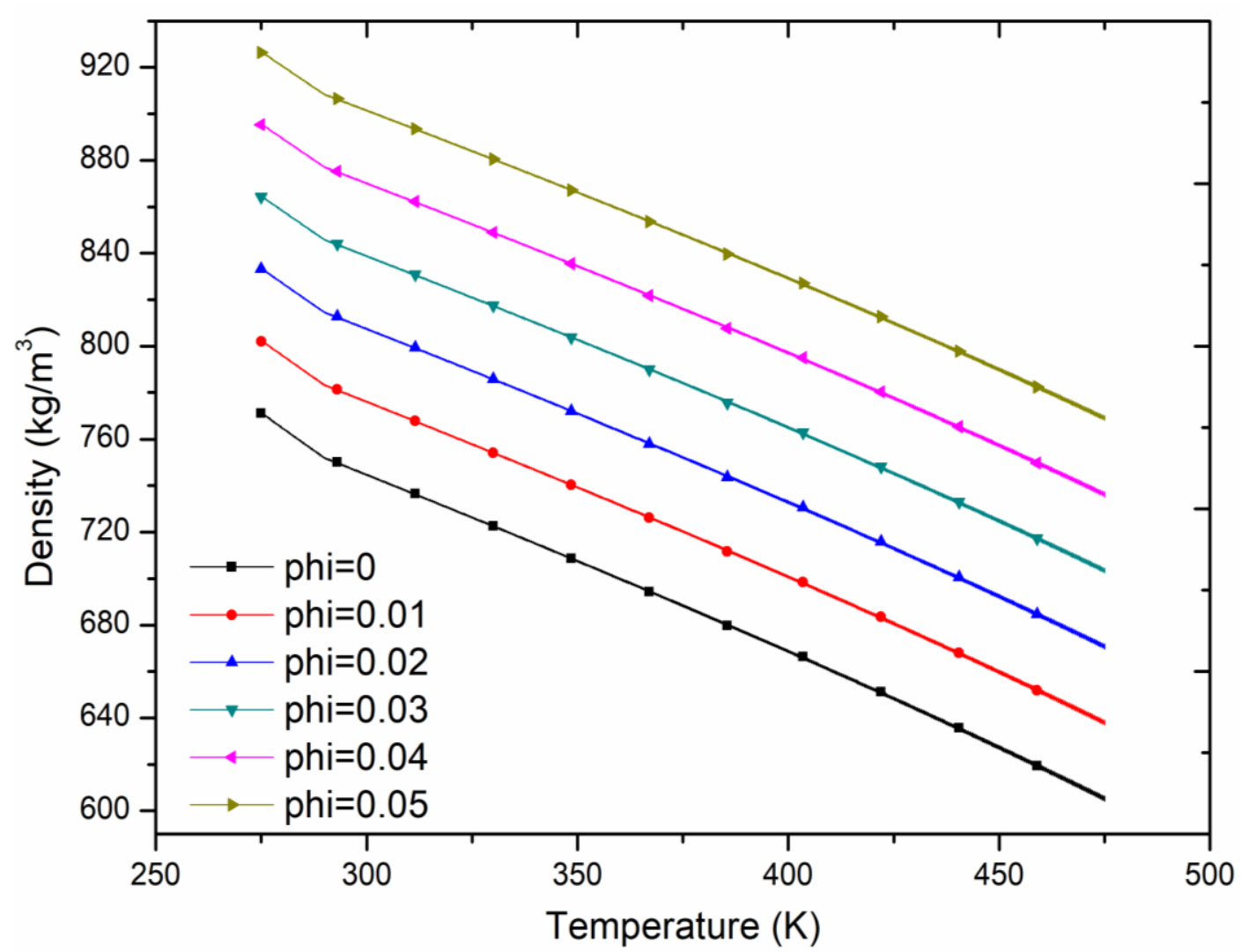

Fig. 3. Density of dodecane and nanofluid

Table- I: Coefficients for developed correlation

\begin{tabular}{|l|l|l|l|l|l|}
\hline \multirow{2}{*}{$\begin{array}{l}\text { Correlation } \\
\text { Coefficients }\end{array}$} & \multicolumn{4}{|l|}{ Pressures $\mathbf{1}$ bar to 10 bar and Temperature 275 K to 475 K } \\
\cline { 2 - 6 } & $\mathbf{p h i = 0 . 0 1}$ & $\mathbf{p h i}=\mathbf{0 . 0 2}$ & $\mathbf{p h i}=\mathbf{0 . 0 3}$ & $\mathbf{p h i}=\mathbf{0 . 0 4}$ & phi=0.05 \\
\hline $\mathbf{R}^{2}$ & 0.999 & 0.999 & 0.999 & 0.999 & 0.999 \\
\hline $\mathrm{p}_{0}$ & 1294.267 & 1324.878 & 1354.771 & 1385.189 & 1415.661 \\
\hline $\mathrm{a}_{1}$ & -4.13238 & -4.21644 & -4.29957 & -4.38583 & -4.47073 \\
\hline $\mathrm{a}_{2}$ & -3.639 & -3.6945 & -3.79553 & -4.00098 & -4.08366 \\
\hline $\mathrm{a}_{3}$ & 1.29304 & 1.32805 & 1.39129 & 1.53346 & 1.5812 \\
\hline $\mathrm{a}_{4}$ & $6.99 \mathrm{E}-04$ & $5.72 \mathrm{E}-04$ & $5.36 \mathrm{E}-04$ & $5.85 \mathrm{E}-04$ & $5.37 \mathrm{E}-04$ \\
\hline $\mathrm{b}_{1}$ & -0.00193 & -0.00192 & -0.00191 & -0.0019 & -0.0019 \\
\hline $\mathrm{b}_{2}$ & $-3.84 \mathrm{E}-07$ & $-6.61 \mathrm{E}-07$ & $-9.21 \mathrm{E}-07$ & $-1.20 \mathrm{E}-06$ & $-1.41 \mathrm{E}-06$ \\
\hline $\mathrm{b}_{3}$ & $-1.18 \mathrm{E}-08$ & $-1.08 \mathrm{E}-08$ & $-9.85 \mathrm{E}-09$ & $-8.94 \mathrm{E}-09$ & $-8.17 \mathrm{E}-09$ \\
\hline $\mathrm{b}_{4}$ & -0.00475 & -0.00464 & -0.00459 & -0.00466 & -0.00459 \\
\hline $\mathrm{b}_{5}$ & 0.00165 & 0.00163 & 0.00164 & 0.00174 & 0.00174 \\
\hline
\end{tabular}

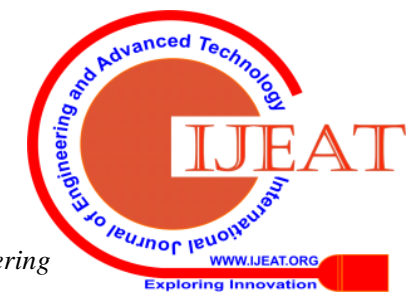




\section{Density of Kerosene Aluminium Nanofluid used for Regenerative Cooling Applications of Thrust Chambers}

Table- II: Errors involved in calculating correlation coefficients

\begin{tabular}{|l|l|l|l|l|l|}
\hline \multirow{2}{*}{$\begin{array}{l}\text { Correlation } \\
\text { Coefficient } \\
\mathbf{s}\end{array}$} & \multicolumn{4}{|l}{ Standard Errors (Effective Density) } \\
\cline { 2 - 6 } & $\begin{array}{l}\mathbf{p h i}=\mathbf{0 . 0} \\
\mathbf{1}\end{array}$ & $\mathbf{p h i = 0 . 0 2}$ & $\mathbf{p h i}=\mathbf{0 . 0 3}$ & $\mathbf{p h i = 0 . 0 4}$ & phi=0.05 \\
\hline $\mathrm{p}_{0}$ & 9.29599 & 8.75982 & 8.56772 & 8.12451 & 8.89823 \\
\hline $\mathrm{a}_{1}$ & 0.38777 & 0.43034 & 0.46654 & 0.49343 & 0.53275 \\
\hline $\mathrm{a}_{2}$ & 4.29081 & 4.73596 & 5.1786 & 5.69855 & 6.15309 \\
\hline $\mathrm{a}_{3}$ & 2.93021 & 3.22329 & 3.51898 & 3.89023 & 4.19308 \\
\hline $\mathrm{a}_{4}$ & 0.06459 & 0.06626 & 0.06734 & 0.06795 & 0.06879 \\
\hline $\mathrm{b}_{1}$ & $\begin{array}{l}2.92 \mathrm{E}-0 \\
4\end{array}$ & $3.42 \mathrm{E}-04$ & $3.79 \mathrm{E}-04$ & $4.00 \mathrm{E}-04$ & $4.40 \mathrm{E}-04$ \\
\hline $\mathrm{b}_{2}$ & $\begin{array}{l}4.23 \mathrm{E}-0 \\
7\end{array}$ & $4.04 \mathrm{E}-07$ & $3.97 \mathrm{E}-07$ & $4.12 \mathrm{E}-07$ & $4.17 \mathrm{E}-07$ \\
\hline $\mathrm{b}_{3}$ & $\begin{array}{l}1.18 \mathrm{E}-0 \\
9\end{array}$ & $1.27 \mathrm{E}-09$ & $1.32 \mathrm{E}-09$ & $1.30 \mathrm{E}-09$ & $1.36 \mathrm{E}-09$ \\
\hline $\mathrm{b}_{4}$ & 0.00549 & 0.00583 & 0.00614 & 0.00651 & 0.00678 \\
\hline $\mathrm{b}_{5}$ & 0.0037 & 0.00392 & 0.00412 & 0.00439 & 0.00457 \\
\hline
\end{tabular}

\section{CONCLUSIONS}

Efficient cooling of thrust chamber is a challenging task for any space agency as much complex systems and large heat loads are involved. However, various modern technologies have been evolved where such challenges are overcome. Usage of kerosene-alumina nanofluid is one such step further to achieve the desired heat transfer rates. Pressure drops can unbalance the economy and size of the pumping systems to maintain the mass flow rates thus in the present study, study has been performed on density of nanofluid and it has been observed that it increases with the volume fraction of nanoparticles and it can affect the Merit number which is one of the parameter which defines heat transfer performance among the thrusters. Further, thermo-hydraulic studies are required to know the optimum input parameters.

\section{REFERENCES}

1. J.-G. Kim, K.-J. Lee, S. Seo, Y.-M. Han, H.-J. Kim, and H.-S. Choi, "Film cooling effects on wall heat flux of a liquid propellant combustion chamber," in 42nd AIAA/ASME/SAE/ASEE Joint Propulsion Conference \& Exhibit, 2006, p. 5196.

2. R. Arnold, D. I. Suslov, and O. J. Haidn, "Film cooling in a high-pressure subscale combustion chamber," J. Propuls. power, vol. 26 , no. 3, pp. $428-438,2010$.

3. J. Song and B. Sun, "Thermal-structural analysis of regenerativelycooled thrust chamber wall in reusable LOX / Methane rocket engines," Chinese J. Aeronaut., vol. 30, no. 3, pp. 1043-1053, 2017.

4. S. R. Shine and S. S. Nidhi, "Review on fi $\mathrm{lm}$ cooling of liquid rocket engines," Propuls. Power Res., vol. 7, no. 1, pp. 1-18, 2018.

5. T.-S. Wang, "Transient three-dimensional startup side load analysis of a regeneratively cooled nozzle," Shock Waves, vol. 19, no. 3, pp. 251-264, 2009.

6. C. H. Marchi, F. Laroca, A. F. C. da Silva, and J. N. Hinckel, "Numerical solutions of flows in rocket engines with regenerative cooling,” Numer. Heat Transf. Part A Appl., vol. 45, no. 7, pp. 699-717, 2004.

7. A. W. Mirand, M. H. Naraghi, and I. Introduction, "Analysis of Film Cooling and Heat Transfer in Rocket Thrust Chamber and Nozzle," no. January, pp. 1-14, 2011

8. M. Pizzarelli, F. Nasuti, and M. Onofri, "Trade-off analysis of high-aspect-ratio-cooling-channels for rocket engines," Int. J. Heat Fluid Flow, vol. 44, pp. 458-467, 2013.

9. D. K. Agarwal, A. Vaidyanathan, and S. S. Kumar, "Investigation on convective heat transfer behaviour of kerosene-A12O3 nanofluid," Appl. Therm. Eng., vol. 84, pp. 64-73, 2015.

10. P. Taylor and S. M. S. Murshed, "Determination of effective specific heat of nanofluids," no. June 2012, pp. 37-41, 2011.

\section{AUTHORS PROFILE}

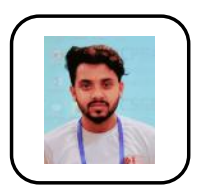

Abhinav Kumar is pursuing his Doctorate in Mechanical Engineering from Lovely Professional University, Punjab, India. He has completed his master's in thermal engineering specialization from Lovely Professional University in 2014 and bachelor's in Mechanical Engineering from Punjab Technical University in 2011. He has published many SCI and Scopus indexed articles in various journals and has attended many international conferences. His area of research is vast including superconducting magnetic energy storage systems, superconducting fault current limiters, high temperature superconducting cable design \& cooling, cryogenic fluid properties, nozzle cooling, computational fluid dynamics and solar energy storage systems. He is one of the reviewers for SCI and Scopus indexed journals and conferences. He has been awarded with University Academic Honor and University Honor Roll for his excellent academic records. He is holding Student IEEE and life membership of Indian Society of Heat and Mass Transfer (ISHMT).

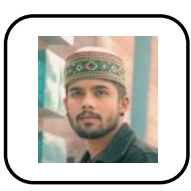

Anil Chamoli is an undergraduate student in Aerospace Engineering from Lovely Professiona University since 2017. He is the Head of Propulsion systems at Euroavia- a technical student organization of Lovely Professional University. $\mathrm{He}$ is working on different area of research including nozzle designs, high temperature materials and rocket fuels. He has participated in many national technical competitions and won prizes.

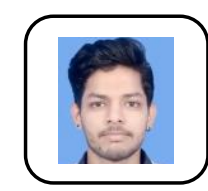

Shahid Khan is an undergraduate student in Aerospace Engineering from Lovely Professiona University since 2017. He has lead a technical competitive event and won $2^{\text {nd }}$ prize in Noviet Space Problem Solution in India. In the early stages of his research career, he is working on rockets fuels and the cryogenic fuel storage in earth-storable heat exchangers.

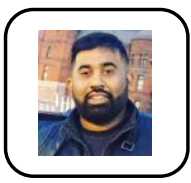

Arfaj Ahamed Anwar is from Toronto, Canada. He has completed his masters in aerospace engineering from Ryerson university Toronto, Canada and bachelors in Aeronautical Engineering from Hindustan College of Engineering. He has about 10 years of experience in aerospace manufacturing industry. Currently working for Collins Aerospace as an MRB engineer. 
Dr. J. V. Muruga Lal Jeyan works with High speed aerodynamics, wind tunnel instrumentation and testing, Was board member of EI Singapore 3 years, 12 plus years of experience in the field of academic, industry and research owner of John plaza shopping mall \& Vijaya apartments. Around 9 years served as Head of Aviation Studies in various University. Had an excellent number of students working under in various topics in and around India. Received RASHTRIYA GAURAV AWARD for meritorious service, by former governor of Tamilnadu \& Assam at a seminar on economic Growth \& National Integration at New Delhi. life member of 1) Aeronautical society of India 2) IAETSD 3) The institute of engineers IE 4) The Indian Science congress ISC Editorial Board Member for few international journals. 